\title{
SIGNIFICANT APPLICATIONS
}

Session Summary

Nils Høeg

Session Chair; nils.hoeg@hydro.com

\section{INTRODUCTORY REMARKS}

Applications or the use of computers is the raison d'être for computers and everything associated with them. We have identified some significant applications conceived and developed in Scandinavia; they also had some lasting impact in the Nordic nations. As it happened, we ended up with examples from Norway.

The first two papers are addressing applications in the Maritime and Offshore Industries, which are among the most significant "clusters" in Norwegian industry. The third paper is a significant application of Nordic networking. The two papers on "Applications and Technologies for Maritime and Offshore Industries" are coordinated.

\section{AUTHORS}

Trond Vahl worked for more than twenty years in the Veritas Group, one of the world's leading ship classification and design companies. Vahl was a researcher in mathematical modeling, and systems and programming, and later on Managing Director of Computas, and Deputy Managing Director of the Veritas Group.

Trygve Reenskaug is professor emeritus of informatics at the University of Oslo. He has 40 years experience in software engineering research and the development of industrial strength software products. He has extensive 
teaching and speaking experience including keynotes, talks, and tutorials. The goal of his current research is to understand the nature of the Information Systems of the 21st Century.

Rolf Nordhagen is professor emeritus at the University of Oslo Centre for Information Technology Service (USIT). From 1972 to 1988, he was Director of the Oslo University Computer Centre. As a member of steering groups and boards he was active in creating the Norwegian academic network UNINETT, and the Nordic network NORDUnet. 